\title{
Indirect Pulp Cap
}

National Cancer Institute

\section{Source}

National Cancer Institute. Indirect Pulp Cap. NCI Thesaurus. Code C52576.

A procedure in which the nearly exposed pulp is covered with a protective dressing to

protect the pulp from additional injury and to promote healing and repair via formation of secondary dentin. 